
\title{
SResearch Square
}

\section{Aptamer-Protamine-siRNA Nanoparticles in Targeted Therapy of ErbB3 Positive Breast Cancer Cells}

\section{Xiangshang Xu ( $\nabla$ xsxu@tjh.tjmu.edu.cn )}

Tongji Hospital of Tongji Medical College of Huazhong University of Science and Technology https://orcid.org/0000-0003-3978-401X

Li Li

Tongji Hospital of Tongji Medical College of Huazhong University of Science and Technology

Xiaolan Li

Tongji Hospital of Tongji Medical College of Huazhong University of Science and Technology

\section{Deding Tao}

Tongji Hospital of Tongji Medical College of Huazhong University of Science and Technology

\section{Peng Zhang}

Tongji Hospital of Tongji Medical College of Huazhong University of Science and Technology

Jianping Gong

Tongji Hospital of Tongji Medical College of Huazhong University of Science and Technology

\section{Research}

Keywords: breast cancer, targeted therapy, nanoparticle, ErbB3, aptamer

Posted Date: July 17th, 2020

DOl: https://doi.org/10.21203/rs.3.rs-42522/v1

License: (c) (i) This work is licensed under a Creative Commons Attribution 4.0 International License. Read Full License

Version of Record: A version of this preprint was published at International Journal of Pharmaceutics on November 1st, 2020. See the published version at https://doi.org/10.1016/j.jpharm.2020.119963. 


\section{Abstract}

Background: RNAi-based technology has achieved good results in both in vitro and in vivo applications, and it is expected to become a good genetic treatment for some diseases, especially neoplastic diseases. But there are still many obstacles in the in vivo application, the most important thing is the lack of an efficient and safe carrier.

Methods: In this study, we designed and constructed a new siRNA delivery, which was named as aptamerprotamine-siRNA nanoparticle (APR). APR was consisted of ErbB3 aptamer, protamine and siRNA. We used Zeta nanosize to detect the size of APR to verify whether it is a nano-scale compound. We use the FAMRNA to replace the siRNA to detect whether APR could recognize and enter ErbB3 positive MCF-7 cells. The we replaced the siRNA as oncogene suvivin siRNA to detect whether APR could inhibit tumor growth by silence surviving, and replaced siRNA to CDK1 siRNA to detect the cell cycle blocking effect. At last we tested the anticancer effect and safety of APR by carrying survivin siRNA in MCF-7 bearing nude mice.

Results: APR was identified as a nanoscale compound. It showed specific targeting for ErbB3-positive MCF-7 cancer cells. APR has demonstrated the characteristics of inhibiting tumor growth by carrying siRNA against oncogene survivin. APR could also block cell cycle of MCF-7 cells by delivering CDK1 siRNAs. In the ErbB3 positive breast cancer xenograft mice model, APR nanoparticles could inhibit tumor growth and cause tumor regression without any toxicity.

Conclusions: In both in vivo and in vitro applications, APR nanoparticles could be targeted to recognize and enter ErbB3 positive tumor cells, and play a corresponding role by silencing targeted gene expression. APR nanoparticle is expected to become a good tumor treatment option.

\section{Background}

Breast cancer is a quite high incidence disease and very harmful to women health. The main therapeutics of breast cancer are operation, chemotherapy, radiation therapy, endocrine therapy and targeted therapy. ${ }^{1}$ Although some radical operations could prolong the OS (overall survival) and DFS (disease-free survival) of breast cancer patients, tumor recurrence and metastasis are still the main obstacles to be resolved. Chemotherapy and radiotherapy have brought some good results in breast cancer therapy, but they also brought some severe side effects, for example, chemotherapy might induce systemic toxicities, while radiotherapy could cause regional tissues adhesions and normal tissues necrosis. ${ }^{2,3}$ Targeted therapeutics have been applicated in breast cancer for many years, such as trastuzumab in ErbB-2 positive patients, but the long-term efficacy is still unsatisfactory because of the soon coming resistance. ${ }^{4}$ Therefore, we need to find a high effective, low side effects and little cost strategy in breast cancer targeted therapy.

RNAi-based therapeutics may be good choices for cancer therapy because they could silence specific oncogenes. Large findings on RNAi technology have been published from the day of RNAi discovery in 
Caenorhabditis elegans $s^{5}$ and in mammalian cells. ${ }^{6}$ It has become not only a tool of gene research in laboratory, ${ }^{7,8}$ but also a way to treat disease in clinical trials. ${ }^{9,10}$ But there are still many problems in RNAi in vivo applications, the main of which is the suitable delivery. In recent time, there were several formulations of RNAi in vivo research, such as conjugated with cholesterol or aptamer, ${ }^{11}$ embedded by liposome or lipoplexes, ${ }^{12}$ complexed with peptides or polymers ${ }^{13}$ or fused with antibodies ${ }^{14}$. Although these methods could silence target genes, there were still some problems to be resolved, such as lack or low cell targeting, high cell toxicities or large cost. ${ }^{15}$ Therefore, a more efficient, safer, cheaper and higher specificity siRNA delivery is urgent to be explored.

Here we designed a new delivery of siRNA, which was consisted of protamine and aptamer. We called it as aptamer-protamine-siRNA nanoparticle (APR). In this nanoparticle, protamine is a cationic peptide which could combine with nucleic acids intensely, ${ }^{16}$ and the in vivo safety of protamine has been proved in many studies. ${ }^{17}$ Aptamer is a DNA or RNA ligand generated from SELEX (systematic evolution of ligands by exponential enrichment), ${ }^{18}$ it could recognize and bind to proteins with high affinity and specificity. ${ }^{19}$ According the special biological characteristics of aptamer and protamine, we used these two matters to link to siRNA and constructed the APR nanoparticle. In this particle, protamine acted as a bridge to link aptamer and siRNA on its protein skeleton, aptamer (ErbB3 aptamer) played the role as a recognizer to recognize targeted cells with ErbB3 expressed on cell surface, and siRNA is a therapeutic tool to silence target genes when entering cells. Then we performed the following experiments to verify: (a) whether APR nanoparticles could targeted recognize and enter ErbB3 positive cancer cells; (b) the interfering and anticancer effect of APR nanoparticles on ErbB3 positive cancer cells; (c) the in vivo anticancer effect of APR nanoparticles in tumor xenograft nude mice. In order to prevent degradation of aptamer and siRNA by RNase, we made 2'-OMe modification of the two nucleic acids in nucleotides synthesis process. In this study, we chose an ErbB3 aptamer (A30) according to the sequence reported in a previous study. ${ }^{20}$ ErbB3 expressed highly in some types of breast cancer while absent or very low in normal breast tissues, ${ }^{21}$ thus, we chose MCF-7 breast cancer cell line as the cell target in this research.

\section{Materials And Methods}

\section{Preparation of APR nanoparticle}

ErbB3 aptamer sequence is 5'-CAGCGAAAGUUGCGUAUGGGUCACAUC GCAGGCACAUGUCAUCUGGGCG-3', FAM labled no-target siRNA (FAMsRNA) sequence is: sense strand 5'-UUCUCCGAACGUGUCACGUdTdT, antisense strand 3'-dTdT AAGAGGCUUGCACAGUGCA, siEGFP sequence is: sense strand 5'-GC UGACCCUGAAGUUCAUCdTdT, antisense strand 3'-dTdT CGACUGGGACUUCA AGUAG, sisurvivin sequence is: sense strand 5'-GGACCACCGCAUCUCUACA dTdT, antisense strand 3'dTdTCCUGGUGGCGUAGAGAUGU-5'. siCDK1 sequence is: sense strand 5'ACUUCGUCAUCCAAAUAUAdTdT, antisense strand 3'dTdTUGAAGCAGUAGGUUUAUAU. Dissolved protamine (Sigma- Aldrich, USA) into $0.025 \mu \mathrm{g} / \mu \mathrm{l}$ with sterile PBS, ErbB 3 aptamer into $0.01 \mathrm{nmol} / \mu \mathrm{l}$, siRNA (FAMsRNA, siEGFP and sisurvivin, synthesized by Ribobio company, China) into $0.01 \mathrm{nmol} / \mu \mathrm{l}$, then 
mixed aptamer and siRNA with the same volume, put the mixture into protamine solution (the volume of protamine was the same as aptamer or siRNA) and mixed them with slow shake, the APR nanoparticles were prepared 30 minutes before using.

\section{Cell culture}

MCF-7 breast cancer cells and AGS gastric cancer cells (ATCC, USA) were cultured in DMEM medium (Invitrogen, USA), supplemented with $10 \%$ bovine serum (Hyclone, USA), the temperature was adjusted at $37^{\circ} \mathrm{C}$ with $5 \% \mathrm{CO} 2$ concentration.

\section{Fluorescence microscopy and confocal microscopy}

Cultured MCF-7 cells to exponential growth phase, added APR-FAM nanoparticles $(30 \mu \mathrm{l}, 0.01 \mathrm{nmol} / \mu \mathrm{l})$ into cells, 6 hours later, observed cells under fluorescence microscope (Leica, Germany) and confocal microscope (Leica, Germany). In confocal microscopy assays, cell nucleus was stained by PI (Propidium lodide, Sigma-Aldrich, USA), 0, 3 and 6 hours after adding APR-FAM nanoparticles into cells, detected and recorded the entrance process of APR-FAM into target cells.

\section{Plasmid extraction and cell transfection}

Extracted plasmid pcDNA3.1-EGFP from Escherichia coli (e. coli.) by BioDev-Tech (China) plasmid extraction kit (according to the protocols in the kit), lipofectamine 3000 (Invitrogen) was used to transfect MCF-7 cells with EGFP plasmid.

\section{Flow cytometry detection of FAMsRNA and EGFP expression}

6 hours after adding APR-FAM nanoparticles, harvested cells, washed with PBS gently and then detected the expression of FAMsRNA in cells by Flow cytometry (BD FACSort, USA) at the excitation wavelength of $492 \mathrm{~nm}$.

After adding APRsiEGFP (APRe) nanoparticles $(30 \mu \mathrm{l}, 0.01 \mathrm{nmol} / \mu \mathrm{l})$ into MCF-7 cells to incubate for about 48 hours, detected the expression of EGFP by Flow cytometry at the excitation wavelength of $488 \mathrm{~nm}$.

\section{Cell staining by Hoechst 33258 and DAPI}

Added Hoechst 33258 (Beyotime, China) into MCF-7 cells and put the cells into incubator for about 30 minutes, then washed cells by PBS for 3 times and observed the changes of cell nucleus under fluorescence microscope. For DAPI staining, first fixed cells by $4 \%$ paraformaldehyde for 30 minutes, then added DAPI (Beyotime, China) into cells for about 5 minutes at room temperature, washed cells 3 times by PBS, then observed the staining of cell nucleus by confocal microscope.

\section{RNA extraction and qPCR}

Extracted total mRNAs by Trizol (Invitrogen, USA) as the product protocol, then did the qPCR according to the protocols described as product protocols (Takara, Japan). 
Primers (forward and reverse respectively) used in PCR were listed as below: TCTCAAGGACCACCGCATCT and CCAAGTCTGGCTCGTTCTCA for survivin, CACCAACTGGGACGACATG and CACAGCCTGGATAGCAACG for $\beta$-actin, GATCCAGGATAACGGAGGCT and TCACTTGTGGCCCAGATAGG for BCl-2, CATGGTCCTGCTGGAGTTCGTG and CGTCGCCGTCCAGCTCGACCAG for EGFP, ACTGGCTGATTTTGGCCTTGCC and TGGGAGTGCCCAAAGCTCTGAA for CDK1, GCCCCAACCAAAAGAAAGTCT and AGCTTTGTGCCTTCACTTCCA for Ki67, CATCACTTCCTCCTGCTCTAT and CAGTTGTTGGCAATCTTCTTC for PI3K, GGACAACCGCCATCCAGACT and GCCAGGGACACCTCCATCTC for Akt. All the primers were designed by Primer Primer 5 software, and synthesized by Invitrogen (USA).

\section{Protein extraction and western blotting}

After harvesting cells, added cell lysis buffer (25 mM HEPES, pH 7.4; 150 mM NaCl; $1 \%$ NP-40; 0.25\% sodium deoxycholate; $1 \mathrm{mM} \mathrm{EGTA;} 1 \mathrm{mM} \mathrm{DTT;} 50 \mu \mathrm{g} / \mathrm{mL}$ trypsin inhibitor; $1 \mathrm{mM} \mathrm{PMSF}$; and $10 \mu \mathrm{g} / \mathrm{mL}$ aprotinin) into cells on ice for 30 minutes, centrifuged them at $12000 \mathrm{rpm} 4{ }^{\circ} \mathrm{C}$ for 10 minutes, took the supernatant, added SDS loading buffer and then boiled it at $100^{\circ} \mathrm{C}$ for 5 minutes, performed western blotting analyses. Proteins of different groups were separated by electrophoresis in $12 \%$ sodium dodecylsulfate-polyacrylamide gel electrophoresis (SDS-PAGE), transferred to nitrocellulose membrane

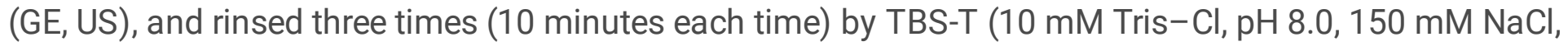
and $0.5 \%$ Tween 20). After 3 hours of incubation at room temperature with the first antibodies (EGFP monoclonal antibody, Santa Cruz (sc-9996); survivin monoclonal antibody, Santa Cruz(sc-17779); $\beta$-actin monoclonal antibody, Santa Cruz (sc-81178); Bcl-2 polyclonal antibody, Boster (A00040-2), Ki67 polyclonal antibody, Boster (PB0065)), incubated with HRP-conjugated IgG (ThermoFisher) for 1 hour, then detected by the enhanced chemiluminescence system (ThermoFisher).

\section{MTT test}

Added $20 \mu$ I MTT ( $5 \mathrm{mg} / \mathrm{ml}$, thiazolyl blue tetrazolium bromide, Sigma-Aldrich) solution to each well (96 well plate), placed on a shaking table, $150 \mathrm{rpm}$ for 5 minutes, incubated $\left(37 \mathrm{C}, 5 \% \mathrm{CO}_{2}\right)$ for 2 hours to allow the MTT to be metabolized, discarded the media, resuspended formazan (MTT metabolic product) in $200 \mu$ I DMSO (dimethyl sulfoxide, Merck), placed on a shaking table, $150 \mathrm{rpm}$ for 5 minutes, and then analyzed optical density at $560 \mathrm{~nm}$ and subtracted background at $670 \mathrm{~nm}$.

\section{Annexin-V/PI multiparameter flow cytometry}

Washed cells twice with cold PBS and then resuspended cells in $1 \times$ Binding Buffer at a concentration of $1 \times 10^{6}$ cells $/ \mathrm{ml}$. Transferred $100 \mu \mathrm{l}$ of the solution $\left(1 \times 10^{5}\right.$ cells $)$ to a $5 \mathrm{ml}$ culture tube. Added $2 \mu \mathrm{I}$ Annexin V-FITC $(20 \mu \mathrm{g} / \mathrm{ml}$, Keygentec) and $1 \mu$ I PI $(50 \mu \mathrm{g} / \mathrm{ml}$, Keygentec), added $400 \mu \mathrm{l}$ of $1 \times$ Binding Buffer to each tube to resuspend cells, and then analyzed apoptotic cells by flow cytometry.

\section{Sub G1 assay}

According to published protocol, ${ }^{22}$ suspend cells at $1-2 \times 10^{6}$ cells $/ \mathrm{ml}$ in $1 \mathrm{ml}$ of PBS in $12 \times 75$ tubes, centrifuge at $200 \mathrm{~g}$ for $5 \mathrm{~min}$, aspirate off the PBS. Resuspend cell pellet in $500 \mathrm{ml}$ of PBS. Fix cells by 
adding $4.5 \mathrm{ml}$ of $70 \%$ cold ethanol to the cell suspension, centrifuge at $400 \mathrm{~g}$ for $5 \mathrm{~min}$ and remove the supernatant, wash cells in $5 \mathrm{ml}$ of PBS and centrifuge at $400 \mathrm{~g}$ for $5 \mathrm{~min}$, remove the supernatant and resuspend cells in $1 \mathrm{ml}$ of DNA staining solution, incubate resuspended cells for at least $30 \mathrm{~min}$ at room temperature in the dark. Analyze cells by flow cytometry, use $488 \mathrm{~nm}$ laser line for excitation. Measure red fluorescence $(4600 \mathrm{~nm})$ and side scatter. Gate-out residual debris, measure hypodiploid and diploid DNA peaks.

\section{Animal studies}

Athymic female nude mice at age of 8 to 10 weeks were obtained from Shanghai Slaccas. The mice were cultured in a temperature and humidity-controlled environment in animal center of Tongji hospital. This experiment was approved by the Institutional Ethics and Animal Care Committee of Tongji Hospital, Huazhong University of Science and Technology, and all procedures involving animals were conducted in accordance with the laboratory animal care and use guidelines adopted by Hubei Experimental Animal Management Regulations (Hubei Province, China). Injected MCF-7 cells to mammary fatty pad with the number of $5 \times 10^{6}$ subcutaneously. When the tumors grew to $200 \mathrm{~mm}^{3}$, divided mice into two subgroups, one group is for anticancer detection and the other group is for mice survival test.

Anticancer test: When tumor size reached $200 \mathrm{~mm}^{3}, 15$ mice were divided into three groups (vehicle blank control group, APRs group, lipofectamine 3000 transfected survivin siRNA as negative control (Lipo-s)), they were injected PBS $(90 \mu \mathrm{l})$, APRs nanoparticles $(90 \mu \mathrm{l}, 0.01 \mathrm{nmol} / \mu \mathrm{l})$ and lipo-siRNA $(90 \mu \mathrm{l}, 0.01 \mathrm{nmol} /$ $\mu \mathrm{l})$ from caudal vein each three days. All the mice were euthanized and tumors were collected after 4 weeks. Tumors were measured by weight and volume. Survivin, bcl-2 and Ki67 expression were detected by $\mathrm{qPCR}$, immunohistochemistry and western blot.

Mice survival test: We divided 15 mice into three groups randomly like in Anticancer tests. When tumor size reached $200 \mathrm{~mm}^{3}$, vehicle PBS $(90 \mu \mathrm{l})$, APRs nanoparticles $(90 \mu \mathrm{l}, 0.01 \mathrm{nmol} / \mu \mathrm{l})$, lipo-siRNA $(90 \mu \mathrm{l}$, $0.01 \mathrm{nmol} / \mu \mathrm{l})$ were injected into caudal vein each three days. We recorded mice death time and terminated the test at 12 weeks after nanoparticles injection, and drew the survival curve of each group.

\section{Immunohistochemistry assay}

Tumors were surgically resected from experimental mice and fixed in $4 \%$ formalin for 24 hours, embedded in paraffin, and sectioned to $4 \mu \mathrm{m}$ depth for immunohistochemistry. The procedure was done according the published paper ${ }^{23}$.

\section{Statistics}

Results are expressed as the mean \pm SD and are analyzed by $t$ tests. Differences were considered to be statistically significant when $p<0.05$.

\section{Results}




\section{APR compound was identified as a nano-scale compound}

We successfully constructed the aptamer-protamine-siRNA compounds. we analyzed the secondary structure of aptamer (ErbB3) (Fig. 1a, use RNA structure 3.5) and protamine strand structure (Fig. 1b, use Raswin software) and found that there were some a-helical regions rich in arginine in protamine strand which could supply the place for nucleotides to bind. Then we drew a sketch diagram of the APR structure as Fig. 1c. As shown in this figure, we supposed that protamine could play the role of a bridge to link aptamer and siRNA nucleotides, the aptamer could recognize and bind the target receptors on cell surface, and when APR bound to target cells, the compounds might be engulfed by cells and then the siRNA could interfere its target gene. The optimal ratio of protamine to total RNA was between 1:4 3:4 (Fig. 1d), which means the suitable aptamer/protamine/siRNA ratio might be 2:1:2 2:3:2, so we chose the media ratio as 1:1:1 to design and construct the APR compounds. Then we detected the compounds size by Zeta nanosize (Zetasizer Nano ZS, Malvern, US) and demonstrated that their diameters were in Gaussian distribution, and the average diameter of them was about $91.07 \mathrm{~nm}$ (Fig. 1e). These results meant that APR compounds were nano-scale particles.

\section{APR nanoparticles exhibited cellular target-specificity}

To evaluate whether APR could enter target cells, we constructed aptamer-parotamine-FAMsRNA (APRFAM) nanoparticle, the FAMsRNA was a non-target double strands RNA labeled by green fluorescence. We chose MCF-7 breast cancer cell line as the test group and AGS gastric cancer cell line as the control group. First, we used immunochemistry and flow cytometry methods to detect the expression of ErbB3 on MCF-7 and AGS cells, and found that ErbB3 overexpressed on MCF-7 cells while very low expressed on AGS cells (Fig. 2a, 2b). We performed the fluorescence microscopy and confocal microscopy analysis to observe the combination and entrance process of APR-FAM to MCF-7 cells. 6 hours after adding APRFAM nanoparticles into exponential growth phase culturing cells, we saw green fluorescence in the MCF-7 cells while nearly nothing in AGS cells (Fig. 2c). By flow cytometry examination, we could see the ratio of APR-FAM expressed in MCF-7 cells $(22.03 \% \pm 2.51 \%)$ was obviously higher than that in AGS cells $(1.04 \%$ $\pm 0.37 \%$ ) (Fig. 2d, 2e). When stained MCF-7 cell's nucleus by PI and observed them by confocal microscope after adding APR-FAM 6 hours, we could see most of the green fluorescence intracellular distributed in cytoplasm and only a little in the nucleus (Fig. 2f). In order to observe the entrance process of APR-FAM into cells, we used confocal microscopy to observe and record the picture after adding APRFAM 0,3 and 6 hours respectively. With the time extension, green fluorescence gradually increased in MCF-7 cells (Fig. 2g). In order to prove the cell targeted characteristics of APR-FAM, we set some comparison group (aptamer-FAMsRNA, protamine-FAMsRNA) to compare the expression of FAM expression. The results showed that FAMsRNA expressed higher in APR-FAM group than that in protamine-FAMsRNA and aptamer-FAMsRNA group (Fig.S1a, S1b). These results indicated that APR nanoparticles could bind to and enter target cells with high specificity.

\section{APR nanoparticles could silence target genes in target cells}


We have proved that APR could recognize and enter target cancer cells, then we should verify whether it could silence the target gene in the target cells. Here we chose EGFP gene to investigate because it is easy to be observed and detected. First of all, we constructed an aptamer-protamine-siEGFP nanoparticle (APRe) as below methods, then transfected MCF-7 cells with pEGFP plasmid by lipofectamine 3000 (Invitrogen, USA) to set up EGFP-expressed MCF-7 cells. 24 hours after transfection, washed cells by PBS (phosphate buffered solution) and added APRe nanoparticles into the transfected cells (untransfected cells with APRe adding as blank control group, transfected cells with PBS vehicle as vehicle group, transfected cells with lipofectamine 3000 transfected siEGFP as another control group). Then we detected the silencing effects of APRe on EGFP by fluorescence microscopy, APRe nanoparticles showed better silencing effects than lipofectamine $3000 \mathrm{did}$ (Fig. 3a). We also detected APRe silencing effect by flow cytometry, the results showed APRe had the best silencing effects (Fig. 3b and 3c, blank group 0.93\% $\pm 0.07 \%$, EGFP group $76.87 \% \pm 3.76 \%$, APRe group $18.19 \% \pm 3.87 \%$, Lipo-siEGFP group $26.57 \% \pm 5.87 \%$ ). qPCR (Fig. 3d) and western blot (Fig. 3e) showed the same results of EGFP expression as flow cytometry detection. These results strongly supported that APR nanoparticles could silence target genes in target cells, and they might become promising anticancer strategies by delivering oncogene siRNAs.

\section{APR nanoparticles exhibited potent anticancer activities by silencing survivin gene}

As the results showed above, APR nanoparticles could silence target gene in specific cells, we wanted to know whether they could become potent anticancer reagents by replacing the siRNA part to an oncogene siRNA. Therefore, in this part, we chose the oncogene survivin, which is a member of inhibitor of apoptosis (IAP) family and plays a very important role on cancer progression. ${ }^{24}$ Some reports showed when survivin was inhibited or knocked out, cancer cells would show obvious apoptosis and proliferation inhibition. $^{25}$

As we known that ErbB3 is a cell membrane protein which is associated to PI3K/Akt signal pathway, and this pathway is very important in tumor progression. In order to know the anticancer effect of APR, we need to figure out whether ErbB3 aptamer has an impact on PI3K/Akt signal pathway, so we synthesized aptamer-protamine-siRNA(nonsense) nanoparticles (APRn) and then added them into MCF-7 cells to incubate for 48hours. Then we used QPCR and western blot to detect PI3K/Akt signal pathway, and found that there were no significant changes on this pathway on both mRNA level and protein level (Fig.S2a, $\mathrm{S} 2 \mathrm{~b}$ and S2c). These results revealed that ErbB3 aptamer didn't have impact on PI3K/Akt by binding to ErbB3, which was the same as other papers reported. ${ }^{26}$

Then we tested the anticancer effect of APR nanoparticles by delivering survivin siRNA. We synthesized aptamer-protamine-sisurvivin nanoparticles (APRs) and then added APRs (vehicle PBS as blank control group and aptamer-protamine-sRNA (no target siRNA) as negative control (APRn)) into MCF-7 cells, cultured cells for 48 hours and harvested cells. By qPCR and western blot tests, we found that APRs could inhibit survivin expression both on mRNA and protein levels (Fig. 4a, 4b). And by western blot (Fig. 4b) we 
could see that cleaved caspase 9 expressed higher in APRs group than in other control groups. Because the cleaved caspase 9 is the activated caspase 9 and survivin could inhibit cell apoptosis by inhibiting caspase 9 activities, we could summarize that APRs could targeted silence survivin and then promote caspase 9 activity to induce more cell apoptosis. The we used MTT tests to demonstrate that APRs could inhibit MCF-7 cells' viabilities more than lipofectamine 3000 transfected survivin siRNA (Fig. 4c). In order to make clear the impact of APRs on cell proliferation, we harvested cells and stained cell nuclei by Hoechst 33258. By fluorescence microscopy, we could see the nuclear staining in the APRs group was significantly heavier than the other two control group (small apoptosis body) (Fig. 4d). We used flow cytometry to detect the apoptosis ratio in each group and found it was much higher in APRs group $(37.90 \% \pm 5.07 \%)$ than in other two groups $(4.15 \% \pm 1.63 \%$ in blank control group and $3.39 \% \pm 1.40 \%$ in negative control group respectively) (Fig. 4e).

In order to prove the cell targeting characteristic of APR nanoparticles in MCF-7 cells, we also tested it in AGS gastric cancer cell line which was an ErbB3 negative cell (Fig. 2a). Western blot results showed APRs nanoparticles could not silence survivin expression as well as lipofectamine transfected sisurvivin method. (Fig.S3a). These results demonstrated that APR nanoparticles could silence target oncogenes in target cancer cells and inhibit cell growth.

\section{APR nanoparticles could block cell cycle by carrying CDKs SiRNA}

For further research about the effects of APR nanoparticles on target cancer cells, we designed a new APR nanoparticle (APRc) which carried CDK1 siRNA. CDK1 is a highly conserved protein that functions as a serine/threonine kinase. ${ }^{27}$ It is a key player in cell cycle regulation, ${ }^{28}$ it could modulate cell cycle as well as a mitotic onset, promote G2-M transition, and regulate $\mathrm{G} 1$ progress and G1-S transition via association with multiple interphase cyclins. In this part, we added APRc (vehicle PBS as blank control group and aptamer-protamine-siRNA (no target siRNA) as negative control) into MCF-7 cells to incubate for 48 hours and then harvested cells for next detections. First of all, we detected the interfering effects of CDK1 expression on mRNA and protein levels by qPCR and western blot assay, the obviously lower expression in APRc group indicated that APRc could effectively silence CDK1 in MCF-7 cells (Fig. 5a, 5b). And from western blot, we also could see that suvivin and Ki 67 expressed lower in APRc group than in other control groups, while cleaved caspase 9 expressed higher in APRc group. The reason might be that APRC nanoparticle could silence CDK1, and then induce survivin down expression (like reported in other papers 29,30 ) and activate caspase 9 to cause more cell apoptosis. Secondly, we analyzed the cell cycle distribution and cell apoptosis by sub-G1 assay. ${ }^{22}$ The results showed cell apoptosis was higher in APRc group than that in other groups, and the G2-M phase cancer cells ratio was much higher in APRc group than in other groups (Fig. 5c,5d,5e). Finally, we used MTT assay to detect the impact of APRc on cancer cells' viabilities and found that APRc could inhibit cell growth significantly as Fig. $5 f$ showing. These data demonstrated that APR nanoparticles could cause cell apoptosis and inhibit cell progression by delivering CDK1 siRNA to block cell cycle transition. 


\section{APR nanoparticles could inhibit tumor growth in ErbB3 positive breast cancer xenograft mice models}

In the cell tests, we proved that APR nanoparticles could silence target genes in target cells and induce cancer cell growth inhibition by silencing oncogene or CDKs. But how about it in in vivo status? Therefore, in this part we set up a xenograft model in which MCF-7 cells were injected subcutaneously into immunodeficient mice. When tumor size reached $200 \mathrm{~mm}^{3}$, all the mice were divided into three groups (vehicle negative control group (NC), APRs group, lipofectamine 3000 transfected survivin siRNA group (Lipo-s)). They were treated by vehicle PBS, APRs nanoparticles, lipo-siRNA via caudal vein every three days. Tumors were collected after 4 weeks treated and analyzed. As shown in Fig. 6a, the tumors size and weight in APRs group were much smaller than those in other two groups. We used immunohistochemistry assay was used to detect the expression of survivin, Ki67 and caspase 9 in tumor tissues, and found that survivin and Ki67 were both lower in APRs group than the other two groups while caspase 9 expressed much higher than the other groups (Fig. 6b, 6c). We also detected them by western blot, the results were the same as immunohistochemistry tests (Fig. 6d), APRs could silence survivin and cause caspase 9 induced cell apoptosis in vivo.

In this in vivo study, we measured mice survival time and draw the survival curve to show the longtime anticancer effects of APRs nanoparticles. We divided 15 mice into three groups randomly, they were labelled as NC group, APRs group and Lipo-s group like above. When the tumor size reached $200 \mathrm{~mm}^{3}$, vehicle PBS, APRs nanoparticle, lipofectamine 3000-survivin siRNA were injected into mice via caudal vein every three days, recorded mice death time and terminated the test at 12 weeks after injection. Then we drew the survival curve of each group (Fig. 6e). All the mice in NC group were died of tumor burden before 11 weeks, while there were 4 mice alive in APRs group and 3 mice alive in Lipo-s group. APRs did not cause toxic reactions and death to mice in these tests but one mouse in Lipo-s group was died of lipofectamine 3000 toxicity 8 weeks later, there was both one mouse in Lipo-s and APRs group died of large tumor burden. These results demonstrated that APR nanoparticles could play important roles in anticancer activities in ErbB3 positive tumors in vivo, and they didn't show obvious toxicity in the nude mice model. Therefore, we can conclude that APR is expected to be a potential method of cancer treatment.

\section{Discussion}

Targeted therapy is very important in tumor therapy nowadays. Although we have achieved some success in some types of tumors via protein inhibitors and monoclonal, most of tumors are still lack of effective targeted therapeutics. ${ }^{31}$ Small inhibitors always have many side effects and undesirable toxicities because they couldn't inhibit whole functions of the protein and they always have off-target effects, ${ }^{32}$ while the monoclonal antibodies always show quick drug resistance. RNA interference (RNAi) technology was first described in Caenorhabditis elegans, it is a 21-23 nucleotides RNA which could degrade the cognate mRNA. ${ }^{5}$ Many research have been reported to prove the application of exogenous 
RNAi in mammalian cells could silence target gene expression, which turned on RNAi based therapeutics. ${ }^{33}$ Scientists tried to turn RNAi into a tool for disease especially targeted tumor therapy, because RNAi is a gene targeted, simply to design way. But there still have many obstacles on the road to the clinical use of RNAi, main of which are lack of a high effective and safe delivery, and the undesirable off-target effects. ${ }^{34}$ Nanoparticles are considered to be a potential good carrier for converting RNAi to clinical use. ${ }^{35}$ Therefore, in this study, we constructed a nanoparticle APR to deliver siRNA to target cells.

The APR nanoparticle is made up of three parts, an ErbB3 aptamer, a protamine protein and a siRNA. Aptamers are single stranded DNA or RNA molecules which could bind to protein or other big molecules, they are always isolated by systematic evolution of ligands by exponential enrichment (SELEX) which was first reported in 1990 by Sullenger et al. ${ }^{36}$ Aptamers could bind to their targets with high affinity and high specificity, which is similar to antibodies, but aptamers have more advantages than antibodies such as simple artificial synthesis and low cost. ${ }^{37}$ Aptamers owe better tolerance to environment because they can fold reversibly and more thermostable. In previous studies, it was found that aptamer was less likely to produce immune reactions than monoclonal antibodies when used in vivo. ${ }^{38}$ Aptamer is easy to be degraded by DNase or RNase, but we can modify it in 2' $\mathrm{H}$ (DNA) or 2'OH (RNA) position of the ribose ring of pyrimidines with a 2' $\mathrm{F}$ or 2'OMe. ${ }^{39}$ Therefore, in this study, we synthesized ErbB3 aptamers with 2'OMe modification to enhance the stability and affinity. ErbB3 also known as HER3 (human epidermal growth factor receptor 3), which is a member of the epidermal growth factor receptor (EGFR/ERBB) family of receptor tyrosine kinases. ErbB3 is a membrane protein expressed highly in some breast cancers. ${ }^{40}$ But there is no strong evidence to prove that ErbB3 is associated with tumor growth and progression but is associated with targeted therapeutic resistance in numerous cancers by the ErbB2-ErbB3 heterodimer. ErbB3 aptamer used in this study was reported by Ralf Landgraf et al in $2013,{ }^{20}$ and it was proved to bind ErbB3 specially on MCF-7 cell surface. In our study, we identified the high expression of ErbB3 on MCF-7 cells.

Protamine is the key point in APR nanoparticle because it plays the role of a bridge to link aptamer and siRNA. Protamine is a small arginine-rich nuclear protein which replaces histones in spermatogenesis and is believed essential in sperm head condensation and DNA stabilization. ${ }^{41} \mathrm{It}$ is safe in medical use such as mixed with insulin to increase the duration of insulin action, used in cardiovascular surgery and used as a drug to prevent obesity. ${ }^{42,43}$ Thus, we chose protamine as the nanoparticle's skeleton to deliver aptamer and siRNA.

As reported before, if the delivery particle is larger than $100 \mathrm{~nm}$ in diameter, it would be trapped by reticuloendothelial system and cause the degradation by the activated monocytes and macrophages. ${ }^{44}$ In our study, we detected APR size and found it was smaller than $100 \mathrm{~nm}$, which means APR is a nanoscale compound, so it is not easy to be eliminated by monocytes and macrophages in vivo applications. Then we found that APR nanoparticles could recognize, bind and enter target ErbB3 positive cells, and the number of nanoparticles entering the cell is time-dependent. We used APR to carry oncogene survivin siRNA to constructed APRs nanoparticle and tested the impact of it on MCF-7 cells, the results showed 
APRs could silence survivin expression and induce cell apoptosis and proliferation inhibition. We also found that APR nanoparticles could interfere cell cycle transition by delivering CDK1 siRNA. These results mean that APR nanoparticle could enter ErbB3 positive cells and silence target genes, and it could be used to inhibit this type of tumor's growth by carrying oncogene or CDKs siRNA.

In order to understand the effectiveness and safety of APR in vivo, we used APRs to test in an ErbB3 positive xenograft model of breast cancer, and found it showed the same impact on inhibiting tumor growth by silencing survivin expression. It was worth mentioned that the modification of 2'OMe of pyrimidines in ErbB3 RNA aptamers seemed to be very essential for APR in vivo application, because this modification will help aptamer to avoid rapid degradation caused by RNase. And in this in vivo test, we did not find the death of mice caused by nanoparticles, which indicated that APR nanoparticles were safe reagents. Therefore, APR nanoparticle is suitable for in vivo application, and it is expected to become an optional strategy for tumor therapy in the future.

\section{Conclusions}

In this study, we successfully constructed a new siRNA nanoscale delivery APR nanoparticle, and proved that APR could recognize and enter target cancer cell (ErbB3 positive cell) and then silence target gene by siRNA in in vitro and in vivo tests. However, if we replace the aptamer to another one which could bind to another cell surface receptor, or deliver some other siRNAs to interfere some other key genes in cell fates, the nanoparticle could be adapted to generate therapeutics to treat wide variety of tumors or diseases. APR nanoparticle is different from some reported nanoparticles, ${ }^{8-12}$ because it has the characteristics of dual targeting (cell targeted, gene targeted), and we didn't find any severe toxicities in mice models. Of course, the safety of in vivo applications should be further proved by large sample tests and biodistribution tests in animals. We believe that APR nanoparticles will hopefully become an ideal choice for targeted tumor therapy in the future.

\section{Declarations}

\section{Ethics approval and consent to participate}

All the animal tests performed in this study were approved by the Institutional

Animal Care and Use Committee of Tongji Hospital, Tongji Medical College, Huazhong University of Science and Technology.

\section{Consent for publication}

Not applicable.

\section{Availability of data and materials}


The datasets used and analyzed during the current study are available from the corresponding author on reasonable request.

\section{Competing interests}

The authors declare that they have no competing interests.

\section{Funding}

This work was supported by National Natural Science Foundation of China (81171927) and Natural Science Foundation of Hubei Province (2014CFB198).

\section{Authors' contributions}

X.X planned and carried out experiments, analyzed and interpreted data, and wrote the manuscript. L.L performed animal experiments and analyzed data. P. Z designed and performed some experiments. X.L and D.T analyzed data and contributed to the interpretation of data. J.G provided supervision, intellectual input throughout the project, and reviewed the manuscript. All authors read and approved the final manuscript.

\section{Author details}

1. Department of Gastrointestinal Surgery, Tongji Hospital, Huazhong University of Science and Technology. ${ }^{2}$. Department of Obstetrics and Gynecology, Tongji Hospital, Huazhong University of Science and Technology. ${ }^{3}$. Cancer research Institute, Tongji Hospital, Huazhong University of Science and Technology.

\section{Acknowledgements}

We thank Miss Cheng Chen (MSc, MBA) for revising the language problems of this manuscript.

\section{References}

1.Sparano JA, Gray RJ, Makower DF, et al. Prospective Validation of a 21-Gene Expression Assay in Breast Cancer. N Engl J Med. 2015;373(21):2005-2014.

2. Allan JM, Travis LB. Mechanisms of therapy-related carcinogenesis. Nat Rev Cancer. 2005;5(12):943955.

3.Hendry JH. Genomic instability: potential contributions to tumour and normal tissue response, and second tumours, after radiotherapy. Radiother Oncol. 2001;59(2):117-126.

4.Swain SM, Baselga J, Kim SB, et al. Pertuzumab, trastuzumab, and docetaxel in HER2-positive metastatic breast cancer. N Engl J Med. 2015;372(8):724-734. 
5.Fire A, Xu S, Montgomery MK, Kostas SA, Driver SE, Mello CC. Potent and specific genetic interference by double-stranded RNA in Caenorhabditis elegans. Nature. 1998;391(6669):806-811.

6.Elbashir SM, Harborth J, Lendeckel W, Yalcin A, Weber K, Tuschl T. Duplexes of 21-nucleotide RNAs mediate RNA interference in cultured mammalian cells. Nature. 2001;411(6836):494-498.

7.Hornung V, Guenthner-Biller M, Bourquin C, et al. Sequence-specific potent induction of IFN-alpha by short interfering RNA in plasmacytoid dendritic cells through TLR7. Nat Med. 2005;11(3):263-270.

8. Reynolds A, Anderson EM, Vermeulen A, et al. Induction of the interferon response by siRNA is cell typeand duplex length-dependent. RNA. 2006;12(6):988-993.

9.Bitko V, Musiyenko A, Shulyayeva O, Barik S. Inhibition of respiratory viruses by nasally administered siRNA. Nat Med. 2005;11(1):50-55.

10.Soutschek J, Akinc A, Bramlage B, et al. Therapeutic silencing of an endogenous gene by systemic administration of modified siRNAs. Nature. 2004;432(7014):173-178.

11.McNamara JO 2nd, Andrechek ER, Wang Y, et al. Cell type-specific delivery of siRNAs with aptamersiRNA chimeras. Nat Biotechnol. 2006;24(8):1005-1015.

12.Morrissey DV, Lockridge JA, Shaw L, et al. Potent and persistent in vivo anti-HBV activity of chemically modified siRNAs. Nat Biotechnol. 2005;23(8):1002-1007.

13.Schiffelers RM, Ansari A, Xu J, et al. Cancer siRNA therapy by tumor selective delivery with ligandtargeted sterically stabilized nanoparticle. Nucleic Acids Res. 2004;32(19):e149.

14.Song E, Zhu P, Lee SK, et al. Antibody mediated in vivo delivery of small interfering RNAs via cellsurface receptors. Nat Biotechnol. 2005;23(6):709-717.

15.de Fougerolles A, Vornlocher HP, Maraganore J, Lieberman J. Interfering with disease: a progress report on siRNA-based therapeutics. Nat Rev Drug Discov. 2007;6(6):443-453.

16.Futaki S, Suzuki T, Ohashi W, et al. Arginine-rich peptides. An abundant source of membranepermeable peptides having potential as carriers for intracellular protein delivery. J Biol Chem. 2001;276(8):5836-5840.

17.Brange J, Langkjaer L. Insulin formulation and delivery. Pharm Biotechnol. 1997;10:343-409.

18.Tuerk C, Gold L. Systematic evolution of ligands by exponential enrichment: RNA ligands to bacteriophage T4 DNA polymerase. Science. 1990;249(4968):505-510.

19.Farokhzad OC, Jon S, Khademhosseini A, Tran TN, Lavan DA, Langer R. Nanoparticle-aptamer bioconjugates: a new approach for targeting prostate cancer cells. Cancer Res. 2004;64(21):7668-7672. 
20.Chen $\mathrm{CH}$, Chernis GA, Hoang VQ, Landgraf R. Inhibition of heregulin signaling by an aptamer that preferentially binds to the oligomeric form of human epidermal growth factor receptor-3. Proc Natl Acad Sci U S A. 2003;100(16):9226-9231.

21.Mu Q, Kievit FM, Kant RJ, Lin G, Jeon M, Zhang M. Anti-HER2/neu peptide-conjugated iron oxide nanoparticles for targeted delivery of paclitaxel to breast cancer cells. Nanoscale. 2015;7(43):1801018014.

22. Riccardi C, Nicoletti I. Analysis of apoptosis by propidium iodide staining and flow cytometry. Nat Protoc. 2006;1(3):1458-1461.

23.Liu D, Li L, Zhang XX, et al. SIX1 promotes tumor lymphangiogenesis by coordinating TGF $\beta$ signals that increase expression of VEGF-C. Cancer Res. 2014;74(19):5597-5607.

24.Mehrotra S, Languino LR, Raskett CM, Mercurio AM, Dohi T, Altieri DC. IAP regulation of metastasis. Cancer Cell. 2010;17(1):53-64.

25.Garg H, Suri P, Gupta JC, Talwar GP, Dubey S. Survivin: a unique target for tumor therapy. Cancer Cell Int. 2016;16:49.

26.Zhang Q, Park E, Kani K, Landgraf R. Functional isolation of activated and unilaterally phosphorylated heterodimers of ERBB2 and ERBB3 as scaffolds in ligand-dependent signaling. Proc Natl Acad Sci U S A. 2012;109(33):13237-13242.

27. Harbauer AB, Opalińska M, Gerbeth C, et al. Mitochondria. Cell cycle-dependent regulation of mitochondrial preprotein translocase. Science. 2014;346(6213):1109-1113.

28. Smith I, Procter M, Gelber RD, et al. 2-year follow-up of trastuzumab after adjuvant chemotherapy in HER2-positive breast cancer: a randomised controlled trial. Lancet. 2007;369(9555):29-36.

29. O'Connor DS, Grossman D, Plescia J, et al. Regulation of apoptosis at cell division by p34cdc2 phosphorylation of survivin. Proc Natl Acad Sci U S A. 2000;97(24):13103-13107.

30.Chandele A, Prasad V, Jagtap JC, Shukla R, Shastry PR. Upregulation of survivin in G2/M cells and inhibition of caspase 9 activity enhances resistance in staurosporine-induced apoptosis. Neoplasia. 2004;6(1):29-40.

31.Papa A, Zaccarelli E, Caruso D, Vici P, Benedetti Panici P, Tomao F. Targeting angiogenesis in endometrial cancer - new agents for tailored treatments. Expert Opin Investig Drugs. 2016;25(1):31-49.

32. Weihua Z, Tsan R, Huang WC, et al. Survival of cancer cells is maintained by EGFR independent of its kinase activity. Cancer Cell. 2008;13(5):385-393.

33.Cullen BR. Induction of stable RNA interference in mammalian cells. Gene Ther. 2006;13(6):503-508. 
34.Pecot CV, Calin GA, Coleman RL, Lopez-Berestein G, Sood AK. RNA interference in the clinic: challenges and future directions. Nat Rev Cancer. 2011;11(1):59-67.

35.Thakur V, Kutty RV. Recent advances in nanotheranostics for triple negative breast cancer treatment. $J$ Exp Clin Cancer Res. 2019;38(1):430.

36.Sullenger BA, Gallardo HF, Ungers GE, Gilboa E. Overexpression of TAR sequences renders cells resistant to human immunodeficiency virus replication. Cell. 1990;63(3):601-608.

37.Baker M. Reproducibility crisis: Blame it on the antibodies. Nature. 2015;521(7552):274-276.

38. Nimjee SM, White RR, Becker RC, Sullenger BA. Aptamers as Therapeutics. Annu Rev Pharmacol Toxicol. 2017;57:61-79.

39.Gotrik MR, Feagin TA, Csordas AT, Nakamoto MA, Soh HT. Advancements in Aptamer Discovery Technologies. Acc Chem Res. 2016;49(9):1903-1910.

40.Patel N, Barrientos A, Landgraf R. The growth factor receptor ERBB2 regulates mitochondrial activity on a signaling time scale. J Biol Chem. 2013;288(49):35253-35265.

41.Powell D, Chandra S, Dodson K, et al. Aptamer-functionalized hybrid nanoparticle for the treatment of breast cancer. Eur J Pharm Biopharm. 2017;114:108-118.

42.Brewer LR, Corzett M, Balhorn R. Protamine-induced condensation and decondensation of the same DNA molecule. Science. 1999;286(5437):120-123.

43. Montellier E, Boussouar F, Rousseaux S, et al. Chromatin-to-nucleoprotamine transition is controlled by the histone H2B variant TH2B. Genes Dev. 2013;27(15):1680-1692.

44.Duarte-Vázquez MA, García-Padilla S, Olvera-Ochoa L, et al. Effect of protamine in obesity induced by high-fat diets in rats. Int J Obes (Lond). 2009;33(6):687-692.

\section{Figures}


a

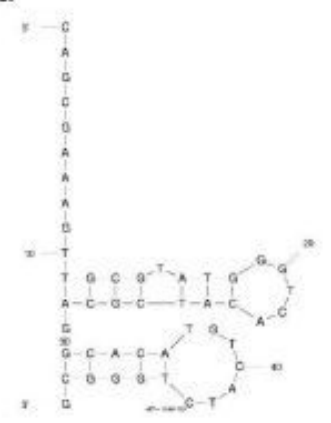

b

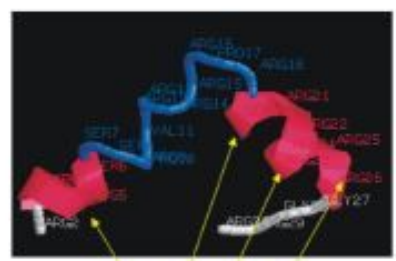

a-hellical regions
C

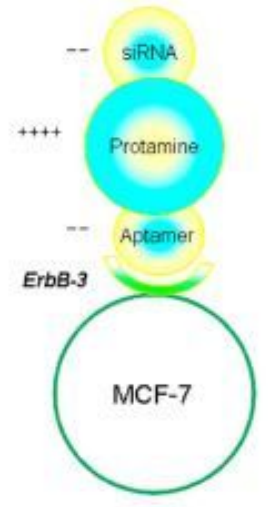

d

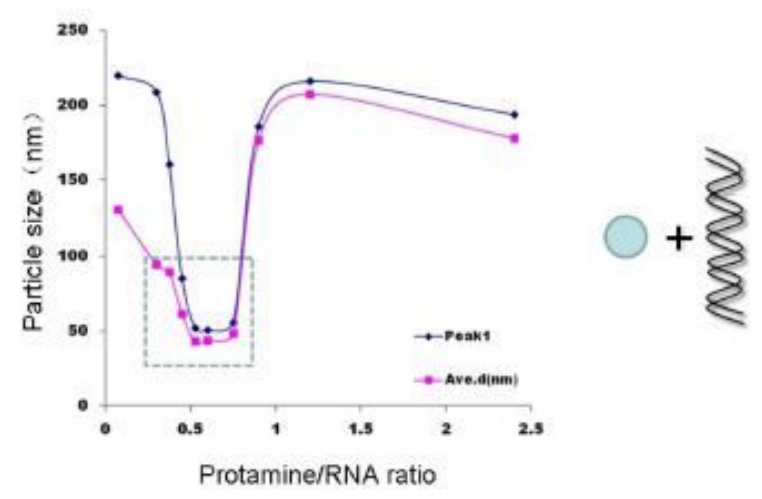

e

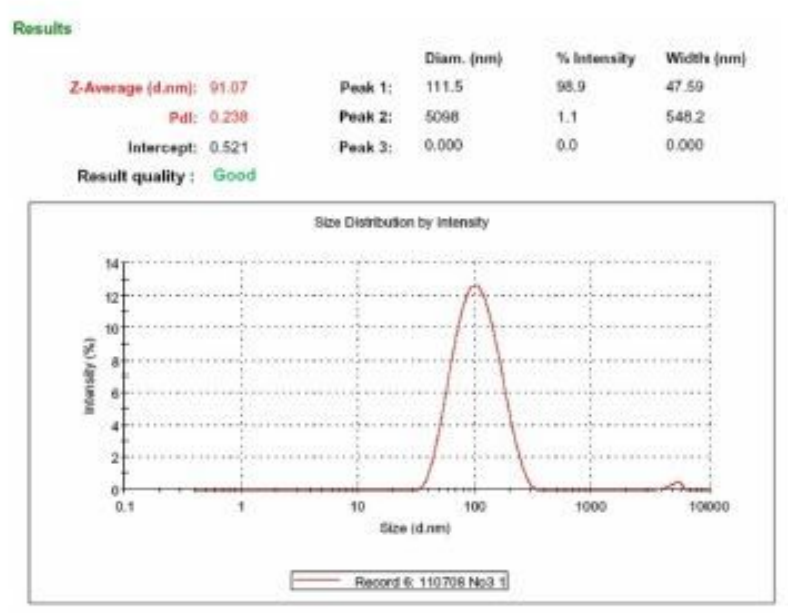

Fig.1

\section{Figure 1}

The structure, size and probable mechanism of APR nanoparticles. (a) The secondary structure of ErbB3 aptamer. (b) The secondary structure of protamine protein. (c) Illustration of how APR nanoparticles silence target gene by recognizing and entering target cancer cells. Protamine is a rich arginine protein

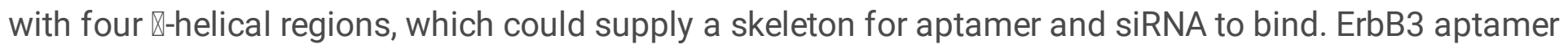
recognizes and binds ErbB3 on the surface of MCF-7 cells, and siRNA silences the target gene when the 
nanoparticle is ingested by the cells. (d) The optimal mixing ratio of the three parts in APR nanoparticles, detected by Zeta nanosize. (e) The composite is nanoscale and Gaussian distributed. As detected by Zeta nanosize, the average diameter of APR was about $91.07 \mathrm{~nm}$. Abbreviations: APR, aptamer-protaminesiRNA; Ave.d, average diameter.

a

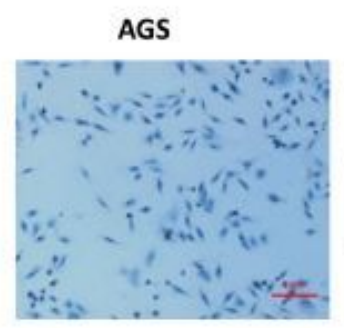

c

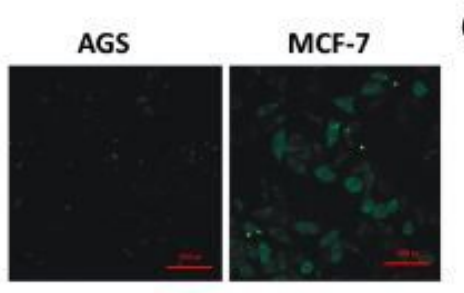

d

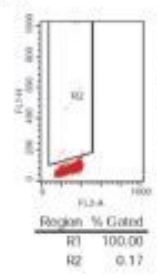

MCF-7
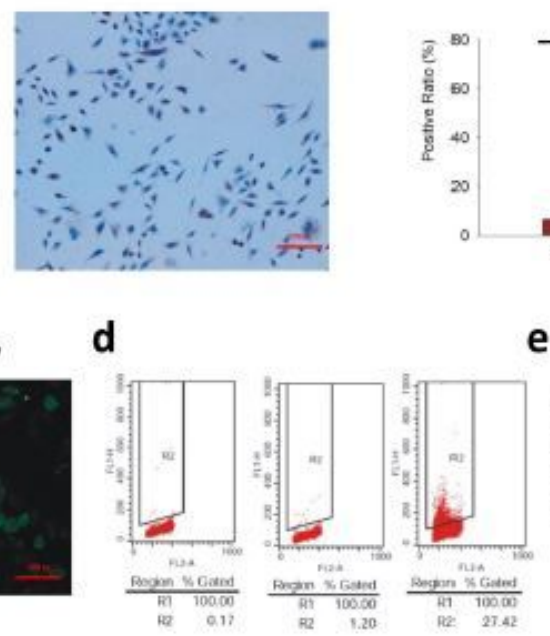

b

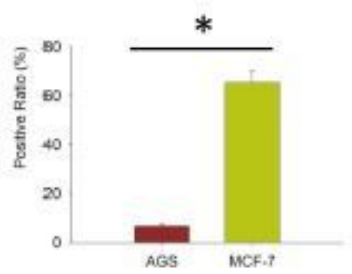

e

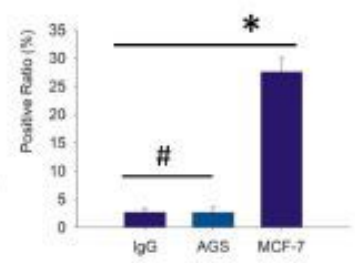

f

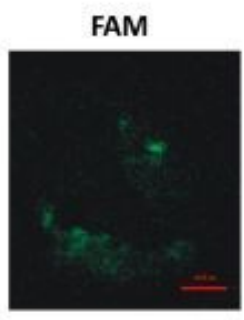

PI

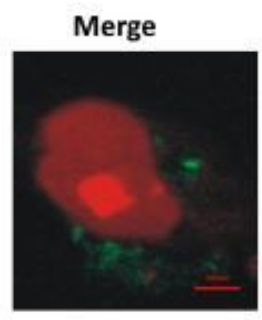

Phase
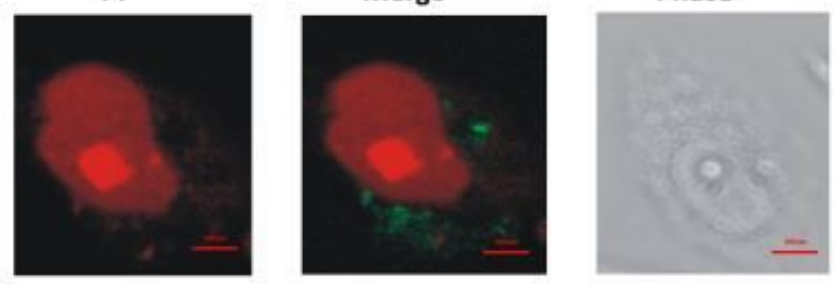

g

Oh

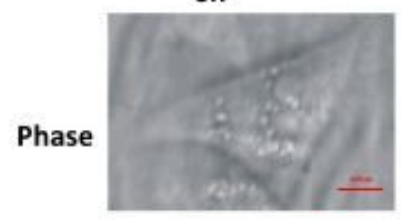

FAM

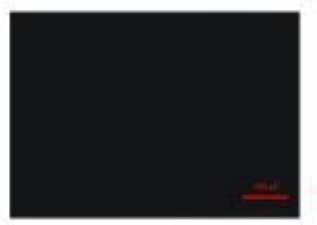

3h
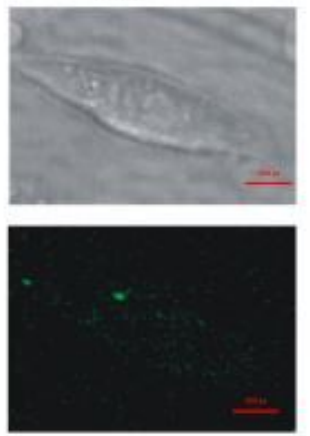

$6 h$
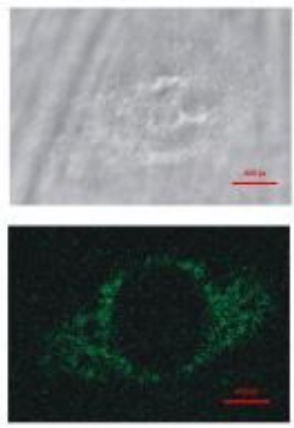

Fig. 2

Figure 2 
APR-FAM nanoparticles have high affinity and specificity to target cells. $(a, b)$ Expression of ErbB3 on AGS gastric cancer cells and MCF-7 breast cancer cells, detected by Immunocytochemistry assay (a) and flow cytometry (b). Scale bar, $20 \mu \mathrm{m}$. (c) Fluorescence microscopy $(\times 200)$ detection of APR-FAM in target cells (MCF-7 cells), AGS cell was as control. Scale bar, $10 \mu \mathrm{m}$. (d, e) Flow cytometry to detect FAM expression in MCF-7 cells and AGS cells, showed by histogram (e). (f) Confocal microscopy detected the distribution of APR-FAM nanoparticles in MCF-7 cells. After adding the nanoparticles 6 hours, FAM fluoresces were mainly distributed in cytoplasm, and merged with PI staining of cell nucleus, only a small number of nanoparticles were found in nucleus, Scale bar, $5 \mu \mathrm{m}$. (g) Intake of APR by target cells is timedependent. We observed and recorded the expression of FAM in MCF-7 cells by confocal microscope after adding APR-FAM 0, 3 and 6 hours, and found FAM expression increasing obviously with time gradually, Scale bar, $5 \mu \mathrm{m}$. Abbreviations: APR-FAM, aptamer-protamine-FAM labeled RNA; PI, Propidium lodide staining; FAM, Carboxy fluorescein. 
a
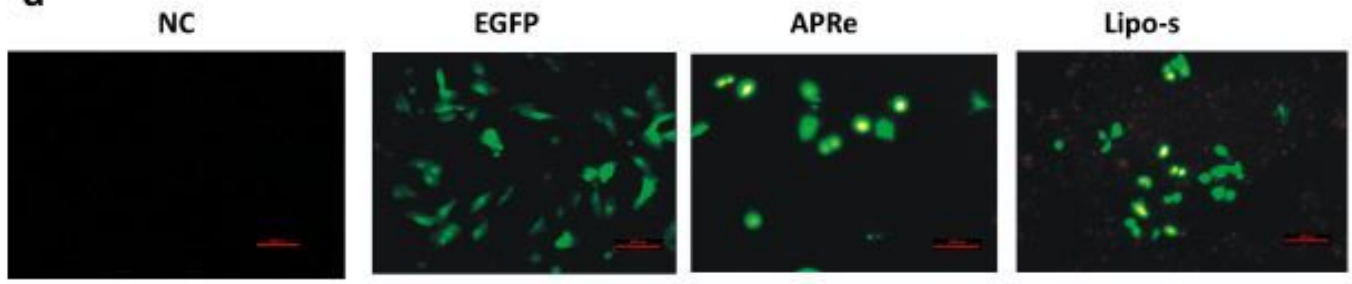

b
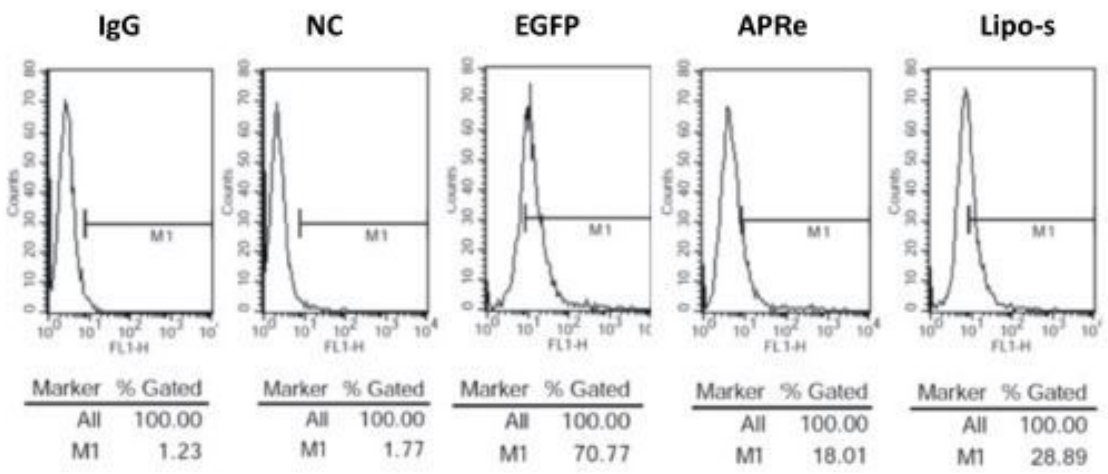

c

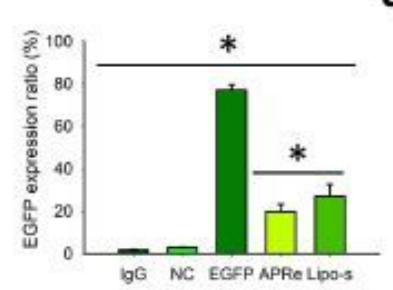

d

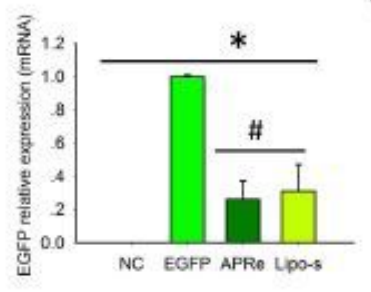

e

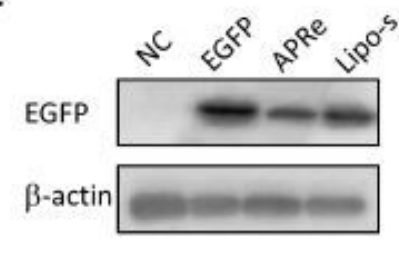

Fig.3

\section{Figure 3}

APRe could target to reduce the expression of EGFP in MCF-7 cells. (a) APRe nanoparticles could significantly reduce EGFP expression, detected by fluorescence microscopy. Scale bar, $10 \mu \mathrm{m}$. (b, c) APRe impact on the expression of EGFP detected by flow cytometry (b) and showed by histogram (c). (d, e) EGFP was downregulated by APRe nanoparticle in MCF-7 cells, detected by qPCR (d) on mRNA level and 
western blot (e) on protein level. Abbreviations: APRe, aptamer-protamine-EGFP siRNA; EGFP, enhanced green fluorescent protein; NC, negative control; lipo-s, lipofectamine 3000 transfected siRNA.

a

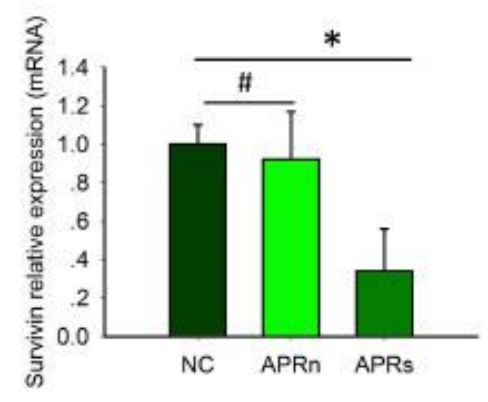

C

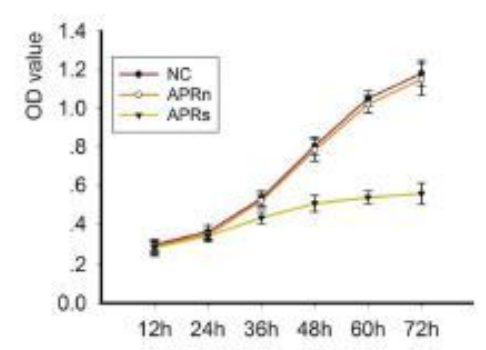

e

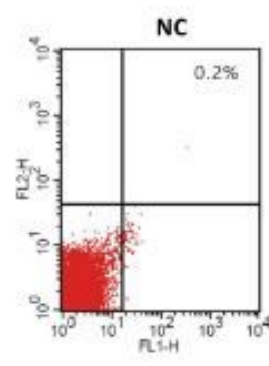

d

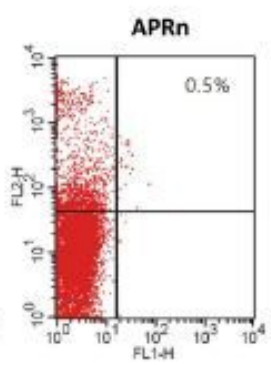

b
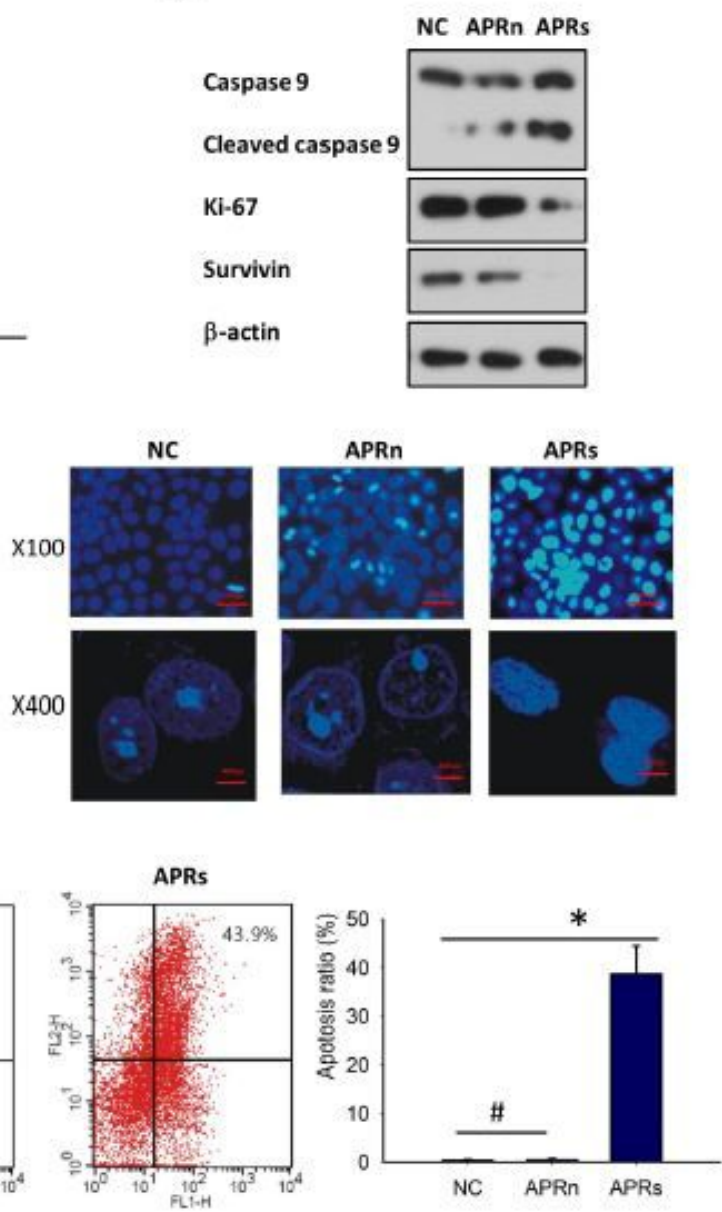

Fig.4

\section{Figure 4}

APRs nanoparticles showed anti-tumor effect by carrying siRNA against oncogene survivin in MCF-7 cells. (a) APRs could reduce survivin expression in MCF-7 cells, detected by $q P C R(n=3, \# P>0.05$, $\left.{ }^{*} \mathrm{P}<0.05\right), \mathrm{NC}$ and APRn were as control group. (b) Western blot analysis of MCF-7 cells with NC, APRn 
and APRs nanoparticles. Immunoblot showed caspase 9, Ki67 and survivin expressions. (c) MTT assay to detect the effect of APRs on cell growth. ( $n=3), N C$ and APRn were as control group. (d) Hoechst 33258 nucleus staining showed cell apoptosis induced by APRs nanoparticles. Scale bar, $20 \mu \mathrm{m}\left({ }^{\star} 100\right), 5 \mu \mathrm{m}$ ( $\left.{ }^{*} 00\right)$. (e) Detected the apoptosis ratio of MCF-7 cells by Annexin V assay in NC, APRn and APRs groups, data was shown in histogram. $(n=3, \# P>0.05, * P<0.05)$. Significance between every two groups was calculated using unpaired two-tailed Student's $t$ test unless otherwise indicated. Data are shown as mean \pm s.d. Abbreviations: APRs, aptamer-protamine-survivin siRNA; NC, negative control; APRn, aptamerprotamine-nonsense siRNA; MTT, methyl thiazolyl tetrazolium. 
a

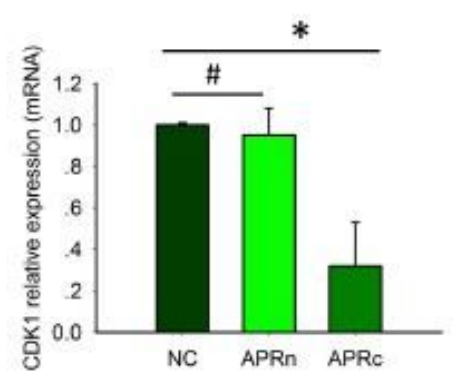

C
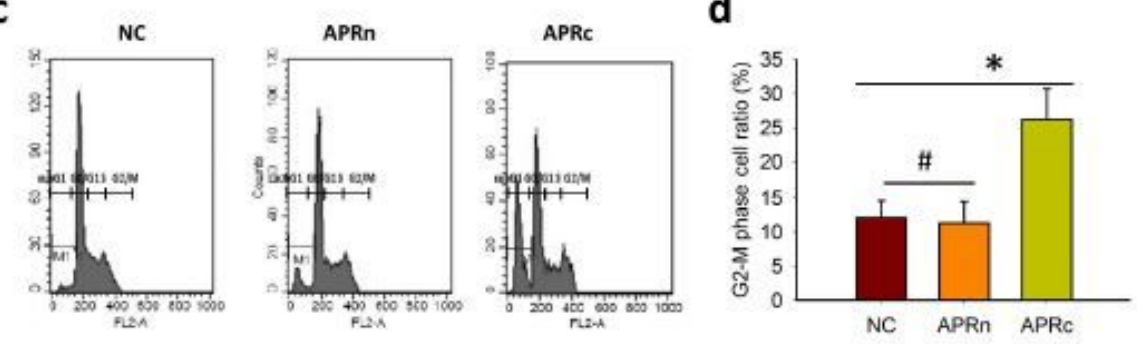

e

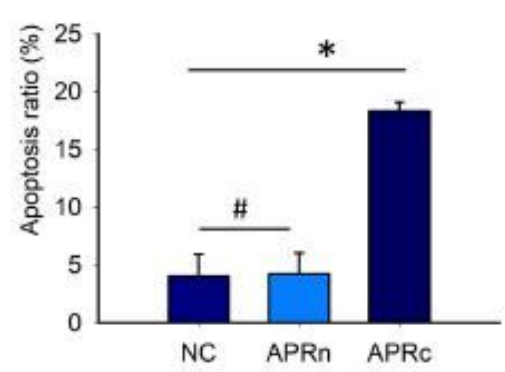

d

b

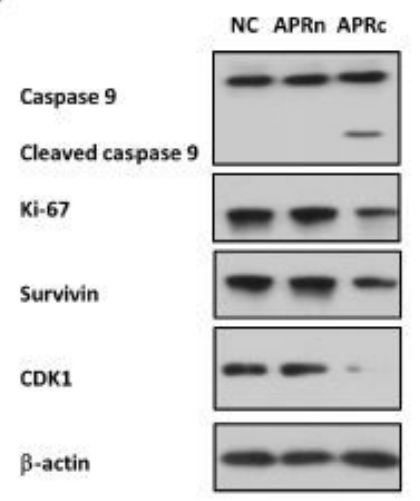

f

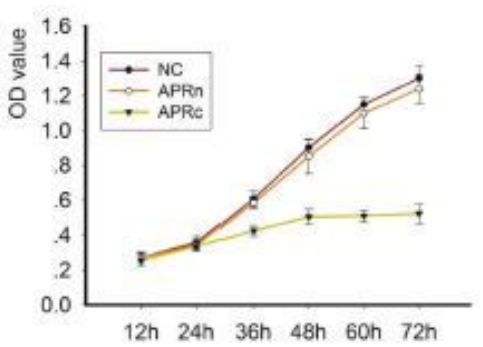

Fig.5

\section{Figure 5}

APRc nanoparticles blocked cell cycles transitions by inhibiting CDK1 expression. (a) qPCR to detect CDK1 expression in MCF-7 cells from negative control, APRn and APRc group. $(n=3, \# P>0.05, * P<0.05)$. (b) Western blot analysis to detect CDK1, survivin, Ki67 and caspase 9 in MCF-7 cells from NC, APRn and APRc group. (c, d, e) Sub-G1 assay to detect cell cycle distribution and cell apoptotic ratio. Flow cytometry detection showed in (c), cell cycle analysis showed APRc could induce G2-M phase cell arrested (d) and 
more cell apoptosis (e) compared to control groups ( $n=3$, \#P>0.05, $\left.{ }^{*}<0.05\right)$. (f) MTT assay to detect MCF-7 cell growth in APRc group compared to NC and APRn groups. $(n=3)$. Significance between every two groups was calculated using unpaired two-tailed Student's $t$ test unless otherwise indicated. Data are shown as mean \pm s.d. Abbreviations: APRc, aptamer-protamine-CDK1 siRNA; NC, negative control; APRn, aptamer-protamine-nonsense siRNA; MTT, methyl thiazolyl tetrazolium.

a

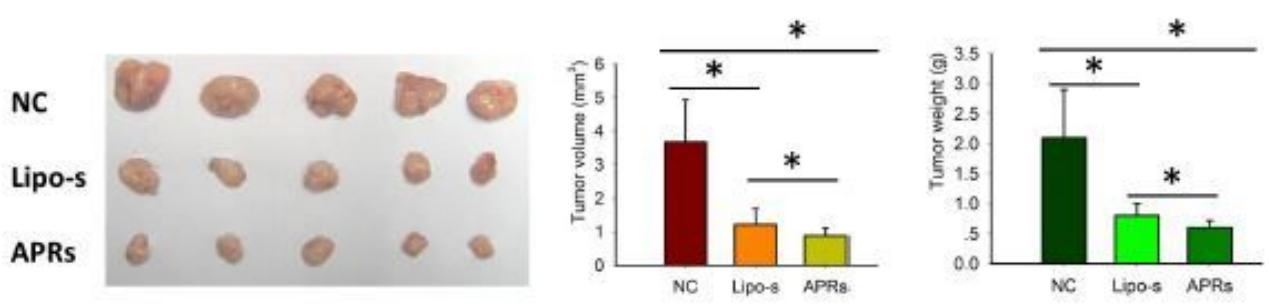

b

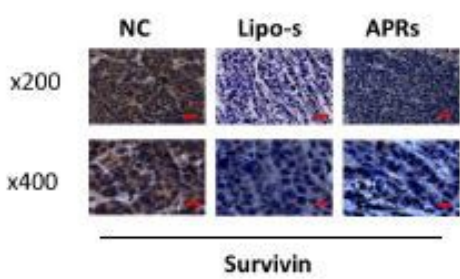

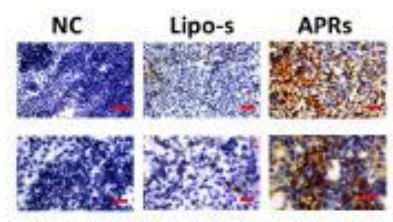

Caspase 9

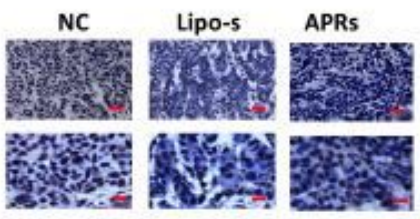

Ki67

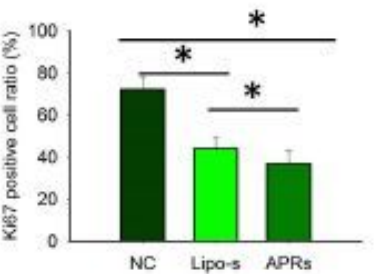

d

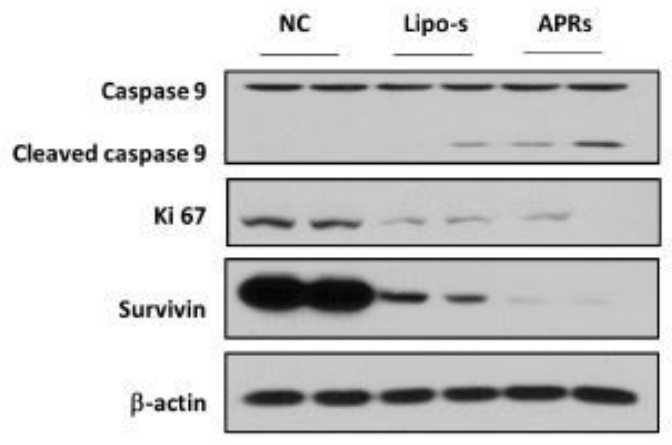

e

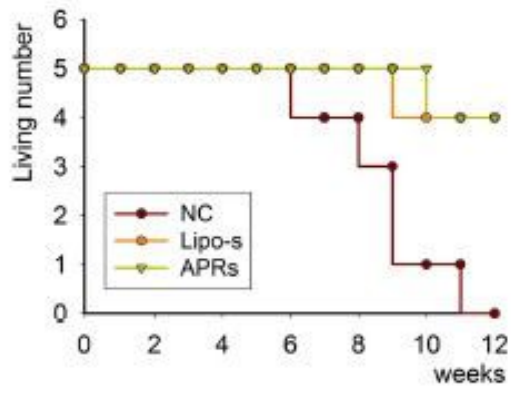

Fig.6

Figure 6 
In vivo experiments to verify the targeted anti-tumor effect of APRs nanoparticles. (a) Xenograft Tumor showed in each group. MCF-7 cells were injected to nude mice's fat pad, and the mice were treated by negative control (PBS), Lipo-s and APRs reagents every three days from tail vein. tumor weight and volume were showed by histogram. $(n=5, \# P>0.05, * P<0.05)$. (b) Immunohistochemistry to detect expression of survivin, caspase 9 and Ki67 in xenograft tumors. scale bar, $\times 200,10 \mu \mathrm{m} ; \times 400,5 \mu \mathrm{m}$. (c) Density analysis of survivin, caspase 9 and Ki67 in xenograft tumors. $\left(n=5, \# P>0.05,{ }^{*} P<0.05\right)$. (d) Western blot to show the expression of survivin, caspase 9 and Ki67 in xenograft tumors (each group showed 2 samples). (e) Mice living curve to reflect the antitumor effects of APRs. $(n=5)$. Significance between every two groups was calculated using unpaired two-tailed Student's t test unless otherwise indicated. Data are shown as mean \pm s.d. Abbreviations: APRs, aptamer-protamine-survivin siRNA; NC, negative control; lipo-s, lipofectamine 3000 transfected siRNA.

\section{Supplementary Files}

This is a list of supplementary files associated with this preprint. Click to download.

- supplementaryfigurelegends.docx

- supplementaryfigurelegends.docx

- SupplementaryFigures.pdf

- SupplementaryFigures.pdf 